\title{
To Treat or Remove: An Economic Model to Assist in Deciding the Fate of Ash Trees Threatened by Emerald Ash Borer
}

\author{
Daniel W. McKenney and John H. Pedlar
}

\begin{abstract}
A model is presented to assist in deciding the fate of ash trees (Fraxinus spp.) threatened by the arrival of emerald ash borer (Agrilus planipennis Fairmaire) in North America. The model tracks ongoing treatment costs versus one-time costs associated with removal and replacement. All future values are discounted following standard economic practice. For each year over a period of interest, the net treatment gain/ loss is calculated, indicating the period of time over which a homeowner would be financially ahead/behind by treating the existing ash tree. The model was populated, with values that may be expected in Canadian conditions, where treatment options are more limited than in the United States. Optional model features include property value premiums, energy savings, runoff and pollution benefits, and ongoing maintenance costs. When these extended benefits and costs are included, positive treatment gains for a medium-sized ash persist for about 17 years. Negative values can be interpreted as a "break-even existence value," an amount a homeowner would be required to pay in order to protect their ash if various other benefit flows fail to compensate the costs. An interactive version of the model is available online (http://gmaps.nrcan.gc.ca/apm/index.php).

Key Words. Agrilus planipennis; Canadian Forest Service Ash Protection Model: CFS-APM; Cost-benefit Analysis; Emerald Ash Borer; Insecticide Treatments; Urban Forest Management
\end{abstract}

To treat or not to treat? That is the question facing many North American ash owners since the arrival of the emerald ash borer (EAB) from Asia (Cappaert et al. 2005). The larvae of EAB feed on the phloem and xylem of ash trees, eventually cutting off the flow of nutrients and usually killing the tree within fives years of initial attack (Siegert et al. 2007). All North American ash species (Fraxinus spp.) can be attacked, although blue ash (Fraxinus quadrangulata Michx.) and Asian ash species appear less susceptible (Anulewicz et al. 2007).

Presented here is a model that assists users (such as homeowners, arborists, and consulting foresters) in deciding whether to treat or remove ash trees threatened by EAB. The model works by tracking, through time, the costs and benefits associated with treating a tree versus removing and replacing it. Sadof et al. (2011) present a useful web-based 'EAB cost calculator,' which serves a similar general function to the model presented here. However, the approach here differs in a number of ways, including the incorporation of a wider range of tree-related costs and benefits. The model is applied in a Canadian context but the model, at least in its simplest form, is general enough to be applied elsewhere. Decisions to protect tree assets can be complex, involving relatively straightforward financial considerations, such as treatment, removal, and replacement costs, as well as more subtle factors, like the influence of tree cover on property values, home energy budgets, and even what economists may term as "existence" values (Krutilla 1967; Boardman et al. 2001), where homeowners may simply "like" the existence of tree cover on their property and are willing to pay for the pleasure of such enjoyment.
Since being discovered in southern Michigan in 2002, EAB has spread rapidly across eastern North America (Prasad et al. 2010). In Canada, the outbreak currently includes much of southern Ontario; major centers such as Toronto, Montreal and Ottawa; and isolated infestations as far north as Sault Ste. Marie, Ontario (Canadian Food Inspection Agency 2010). Over time, EAB is expected to continue its spread across Canada and the United States, decimating ash in both natural and urban settings along the way. Kovacs et al. (2010) estimate the cost to municipalities in the northeastern United States to be $\$ 10.7$ billion over the next decade (see also Sydnor et al. 2011). McKenney et al. (2012) estimate the cost in Canadian municipalities to be upwards of $\$ 2$ billion over the next three decades for street and backyard trees depending on spread and treatment rates. Given its extensive foothold in North America, it is highly unlikely that EAB will be eradicated, although efforts are ongoing to identify effective biological control agents (e.g., Yang et al. 2010).

One option available to property owners is to protect ash trees against EAB attack using insecticide treatments that would be required on an ongoing basis. A variety of products have been tested for this purpose (Herms et al. 2009; McKenzie et al. 2010). In Canada, at the time of writing, three products were registered by Canada's Pest Management Regulatory Agency for use in controlling EAB: TreeAzin ${ }^{\mathrm{TM}}$, ACECAP ${ }^{\circledR} 97$, and Confidor ${ }^{\circledR} 200$ SL. For the current work, the use of the model was illustrated by using treatment costs and application frequencies associated with TreeAzin. This is a systemic insecticide (injected into the trunk of trees) produced from extracts of Neem tree (Azadirachta indi$c a$ ) seeds, which has shown promise in controlling both the larval and egg stages of the EAB life cycle (McKenzie et al. 2010). 


\section{METHODS}

\section{Overview}

Annual costs and benefits are tracked and net gains or losses calculated over a 30-year period and summarized in graphical and tabular formats. The various elements of the model are presented here in a sequential format. The full range of possible model outputs are demonstrated using default settings, for a small diameter at breast height $(15 \mathrm{~cm} \mathrm{DBH})$, medium $(30 \mathrm{~cm})$, and large $(45 \mathrm{~cm})$ ash tree (with cost data and results in 2010 Canadian dollars). It should also be understood that considerable uncertainty exists in the underlying data. Uncertainty does not eliminate the need for careful analysis of options and possible outcomes. A relatively simple sensitivity analysis was carried out by running the model using three plausible values for each of six different parameters while holding the values of all other parameters at the default values for a medium-sized ash located on the west side of the property and within $10 \mathrm{~m}$ of the house. Although default settings were employed for the results presented here, all parameter values can be overridden by model users as required for their specific circumstances. Users can also choose whether or not to include the different benefit categories depending on their particular interests.

\section{Characterizing Existing and Replacement Trees}

To estimate many of the costs and benefits described here, it is necessary to briefly characterize both the existing ash tree, and if applicable, the tree that would replace it under the removal and replacement scenario. Thus, model users are required to identify the size (i.e., DBH) and location of the existing tree, as well as the planned location and type (conifer or deciduous) of the replacement tree (Table 1). This information is important for determining default removal and treatment costs, and for calculating possible energy benefits as described below.

\section{Basic Analysis}

In its most basic form, the model simply tracks and compares the discounted flow of costs associated with treating an existing ash tree through time against the one-time costs associated with its removal and replacement. Both treatment and removal costs are expected to vary with the size of the existing tree. Default removal costs (including stump grinding) are calculated by multiplying the user-supplied DBH value by the corresponding cost estimate (Table 1). Replacement costs are expected to be independent of the size of the tree removed; the default value used here, CAD $\$ 400$, is for the purchase and establishment of a tree that is approximately five years old, $2 \mathrm{~m}$ high, and $4 \mathrm{~cm} \mathrm{DBH}$ (Table 1). The default cost estimates for removal and replacement were obtained from discussions with city foresters and tree removal companies; actual costs are likely to vary considerably depending on local circumstances, such as the availability of arborists, tree condition, and proximity to houses and power lines.

A default cost of $\$ 6.50 / \mathrm{cm} \mathrm{DBH}$ is used for TreeAzin treatments (Table 1; Joe Meating, pers. comm.). This per cm cost may seem high relative to protection options in the United States but reflects the current situation in Canada. For treatment frequency, TreeAzin is currently considered to be effective when applied once every two years (Bioforest 2011; Table 1). Initial costs for treating a tree are calculated by multiplying this value by the user-supplied DBH for the existing tree; however, per $\mathrm{cm}$ costs can be expected to increase over time as the tree grows. To account for this, the DBH of the existing ash tree was estimated for each year of the simulation. Since growth data were not available for Canadian urban areas, a DBH-age equation developed from growth data collected at productive southern Ontario ash plantations with a wide spacing between trees was employed (McKenney et al. 2008):

$$
\mathrm{DBH}=0.8015(\text { age })-0.0029(\text { age })^{2}
$$

A parameter controlling what is called "removal lag" is also included in the model (Table 1). This value describes the number of years that a homeowner opting to remove and replace an ash tree may be able to delay these costs compared to treatment costs that would have to commence before a tree is too heavily infested. Clearly, this parameter involves some judgment regarding how quickly EAB may spread within a community. Given that it takes 3-5 years for EAB to kill a tree (Siegert et al. 2007), and given that insecticides have shown some potential to reverse light infestations (Bioforest 2011), a default lag value of two years was employed.

The model makes use of the standard economic approach of discounting anticipated benefits and costs that occur at different points in time back to the present (Boardman et al. 2001; see also Scott and Betters 2000, for a discussion in the context of urban tree replacement). The discount rate can be thought of as representing the opportunity cost of borrowing and/or an impatience factor or price associated with the decision-maker's view of the cost of time. Costs and benefits can be expected to occur at different points in time, and discounting provides an accepted approach to bring future values to the present. A default discount rate of $4 \%$ (Table 1) was employed-a value commonly used in forest economics (see Portney and Weyant 1999, for discussions on discounting, ranging from an apparent propensity of some individuals to implicitly employ very high discounting to arguments over the use of very low discount rates for issues that have long-term or intergenerational implications, such as climate change or species losses). Again, the discount rate can be changed by users to reflect their own time preference rate or varied to examine the importance of this factor.

\section{Extended Benefits and Costs}

Many benefits have been attributed to urban trees, including home value premiums, energy savings, pollution and runoff reduction, and human health benefits (Dwyer et al. 1992). However, urban trees also incur costs beyond the removal and replacement costs as previously outlined (e.g., pruning, debris cleanup, damage to infrastructure). The work of McPherson et al. (2007) quantifies many of these benefits and costs for urban trees in the northeastern United States. In particular, their values are used here to incorporate annual energy benefits for suitably located trees (Table 1), annual pollution and runoff reduction benefits to society at large (accrued regardless of a tree's location relative to the house), and costs associated with tree maintenance over time (not including initial planting costs, which are covered under basic costs above).

In Table 9 and Table 10 of their work, McPherson et al. (2007) provide the annual benefit and cost estimates at five-year intervals through a tree's life up to age 40 . In order to use these values here, which characterizes benefits and costs in yearly 
Table 1. Input parameters for a model that assists homeowners in deciding whether to treat or remove an ash tree threatened by EAB. Currency is expressed in 2010 Canadian dollars.

\begin{tabular}{|c|c|c|c|c|}
\hline $\begin{array}{l}\text { Type of } \\
\text { information }\end{array}$ & Input value description & Accepted inputs & Default value & $\begin{array}{l}\text { Example } \\
\text { values }^{z}\end{array}$ \\
\hline $\begin{array}{l}\text { Existing } \\
\text { ash tree }\end{array}$ & $\begin{array}{l}\text { Diameter at breast height }(\mathrm{cm}) \\
\text { Cardinal direction from house } \\
\text { Distance from house }(\mathrm{m})^{\mathrm{x}}\end{array}$ & $\begin{array}{l}\text { Real number } \\
\mathrm{n}=\text { north; } \mathrm{s}=\text { south; } \\
\mathrm{e}=\text { east; } \mathrm{w}=\text { west } \\
\text { real number }\end{array}$ & $\begin{array}{l}\text { User supplied } \\
\text { User supplied } \\
\text { User supplied }\end{array}$ & $\begin{array}{l}30 \\
\mathrm{w}\end{array}$ \\
\hline $\begin{array}{l}\text { Replacement } \\
\text { tree }\end{array}$ & $\begin{array}{l}\text { Will a new tree be planted? } \\
\text { Cardinal direction from house } \\
\text { Distance from house }(\mathrm{m})^{\mathrm{x}} \\
\text { Type of tree }\end{array}$ & $\begin{array}{l}\mathrm{y}=\text { yes } ; \mathrm{n}=\text { no } \\
\mathrm{n}=\text { north; } \mathrm{s}=\text { south; } \\
\mathrm{e}=\text { east } \mathrm{w}=\text { west } \\
\text { numeric } \\
\mathrm{c}=\text { conifer } ; \mathrm{d}=\text { deciduous }\end{array}$ & $\begin{array}{l}\text { User supplied } \\
\text { User supplied } \\
\text { User supplied } \\
\text { User supplied }\end{array}$ & $\begin{array}{l}\mathrm{y} \\
\mathrm{w} \\
10 \\
\mathrm{~d}\end{array}$ \\
\hline $\begin{array}{l}\text { Model } \\
\text { parameters }\end{array}$ & $\begin{array}{l}\text { Discount rate }(\%) \\
\text { Removal cost }(\$) \\
\text { Replacement cost }(\$) \\
\text { Treatment cost }(\$) \\
\text { Treatment frequency }(\mathrm{yrs}) \\
\text { Removal lag }(\mathrm{yrs}) \\
\text { Home value }(\$ \times 1000) \\
\text { Estimated contribution of tree } \\
\text { to home value }(\%)\end{array}$ & $\begin{array}{l}\text { Real number } \\
\text { Real number } \\
\text { Real number } \\
\text { Real number } \\
\text { Real number } \\
\text { Real number } \\
\text { Real number } \\
\text { Real number }\end{array}$ & $\begin{array}{l} \\
\text { size dependent }^{v} \\
\$ 400 \\
\$ 6.50 / \mathrm{cm} \mathrm{DBH} \\
2 \\
2 \\
340 \\
0.5\end{array}$ & $\begin{array}{l}4 \\
540 \\
400 \\
6.50 \\
2 \\
2 \\
340 \\
0.5\end{array}$ \\
\hline $\begin{array}{l}\text { Optional } \\
\text { features }\end{array}$ & $\begin{array}{l}\text { Home value benefits } \\
\text { Home energy benefits } \\
\text { Hydrology and pollution benefits } \\
\text { Ongoing maintenance costs }\end{array}$ & $\begin{array}{l}0=\text { off } ; 1=\text { on } \\
0=\text { off } 11=\text { on } \\
0=\text { off } ; 1=\text { on } \\
0=\text { off } ; 1=\text { on }\end{array}$ & $\begin{array}{l}\text { User controlled } \\
\text { User controlled } \\
\text { User controlled } \\
\text { User controlled }\end{array}$ & $\begin{array}{l}1 \\
1 \\
1 \\
1\end{array}$ \\
\hline
\end{tabular}

$\mathrm{z}^{\mathrm{z}}$ These input values were used to generate the output shown in Table 2 and Table 3.

${ }^{y}$ Used to determine home energy benefits; no benefits are accrued for trees to the north of the house.

${ }^{x}$ If $>10 \mathrm{~m}$, then home energy benefits are not calculated.

${ }^{w}$ Home energy benefits are not calculated for conifers because they also shade in the winter

${ }^{v}$ Default removal rates vary with tree size: $\$ 16 / \mathrm{cm}$ for trees $<20 \mathrm{~cm} \mathrm{DBH} ; \$ 18 / \mathrm{cm}$ for trees $>20$ and $<40 \mathrm{~cm} \mathrm{DBH} ; \$ 20 / \mathrm{cm}$ for trees $>40 \mathrm{~cm} \mathrm{DBH}$.

time steps, the values were converted to 2010 Canadian dollars and then fitted using Chapman sigmoidal curves of the form:

$$
y=a\left(1-e^{-b x}\right)^{c}
$$

where $\mathrm{y}$ is the benefit in dollars, $\mathrm{x}$ is the age of the tree, and $\mathrm{a}, \mathrm{b}$, and $\mathrm{c}$ are fitted parameters. These curves, which were fit with $\mathrm{R}^{2}$ values $>0.9$, allowed the values provided by McPherson et al. (2007) to be both interpolated between the five-year intervals provided and extrapolated beyond 40 years of age (Figure 1). Although extrapolation is always a risk, the sigmoidal curves used here followed the trajectory of the data closely and ensured that extrapolated values were not vastly different than values within the range of the data.

There are several other caveats related to the use of this data. First, the values provided by McPherson et al. (2007) are for red maple (Acer rubrum L.), which they consider a typical, "mediumsized" tree. While these values provide a reasonable estimate for replacement trees in most Canadian cities, they may not accurately represent the benefits and costs associated with some replacement trees. Second, their values are based on energy-use patterns and tree growth rates in the northeastern United States. Though the climate in this region is generally similar to that in much of southeastern Canada (where the majority of Canada's urban population resides), it differs substantially from the climate in other Canadian regions (e.g., the west and north); thus, the extended costs and benefits may not be accurate for all parts of the country. Also note that these categories are a mix of what economists would call public and private benefits. A homeowner could directly accrue financial returns for private benefits, such as energy conservation, but not for categories like hydrology and pollution, where the benefits are shared by other members of society. Thus, by including these categories when running the model, users should recognize they will not be the only recipients of these benefits, and these are not likely to result in direct financial gains to the homeowner.

Many studies have examined the relationship between trees and property values (see review in Theriault et al. 2002). Most have concluded that trees do indeed add value to properties; the mean for nine studies cited in Theriault et al. (2002) is a $5.5 \%$ increase in home value, with a range of $-9 \%$ to $19 \%$. However, nearly all of those studies report the changes in home value based on the presence of an unspecified number of mature trees, making it impossible to report those values on a per tree basis. Anderson and Cordell $(1985 ; 1988)$ report a per tree increase in home value of 0.5 to $1 \%$; their minimum value of $0.5 \%$ was used as the default value for this model (Table 1 ). In order to incorporate this value into the model, it was assumed that the presence of a mature yard tree adds $0.5 \%$ to the value of a property; if that tree is treated, then the property value is maintained; if it is cut down and replaced, property value is initially diminished, but slowly returns as the new tree grows. A default property value of $\$ 340,000$ is employed (based on average reported home sale values in Canada: Canadian Real Estate Association 2010; Table 1). Specifically, it is assumed that a percentage of home value is regained each year until the tree attains a DBH of $20 \mathrm{~cm}$ (about 30 years) - at which point the full home value is assumed to have been returned. Growth of the replacement tree is simulated using a DBH-age equation for a plantation-grown maple (McKenney et al. 2008):

$$
D B H=273.9 \times\left[1-e^{(-0.0022 \times A g e)^{1.009}}\right]
$$




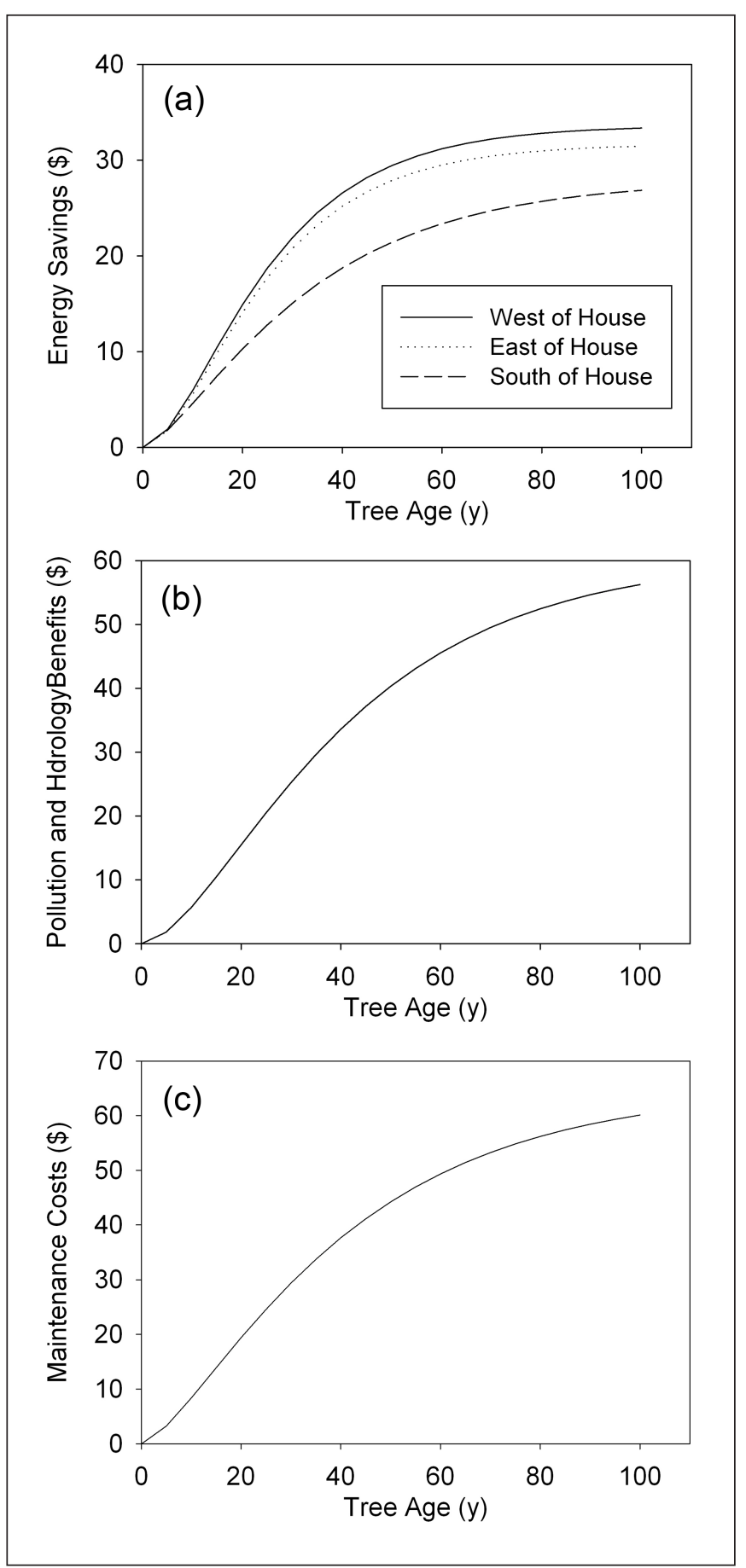

Figure 1. Curves fit to the annual tree benefit and cost data of McPherson et al. (2007; Table 9 and Table 10) that interpolate and extrapolate the relationship between tree age and a) energy savings, b) pollution and runoff reduction, and c) ongoing tree maintenance. Original values were converted to 2010 Canadian dollars before fitting curves.

Although this clearly oversimplifies the potential range in species and growth rates of the replacement tree, experimentation with growth curves from other plantationgrown species found little difference in the final results.

\section{Model Outputs}

The net gain/loss associated with treating infected trees is calculated for each year of the simulation by summing all discounted costs and benefits associated with the treatment and then subtracting the sum of all discounted costs and benefits associated with removal and replacement. Generally, this net present value metric is positive for a period of time until the ongoing cost of treatment eventually outweighs removal and replacement costs. The length of time that treatment gains remain positive gives landowners an indication of how long they can treat a tree and still be ahead of where they would be had they cut it down and replaced it.

Treatment gains (or losses) are also cast as equivalent annual values (A) using the formula:

$$
A=\frac{T G}{\sum_{t=1}^{T}\left(\frac{1}{1+r}\right)^{t}}
$$

where TG is the treatment gain (or loss) in a particular year $(\mathrm{t}$ ), and $r$ is the discount rate (see Boardman et al. 2001 for further details). The equivalent annual value is an alternative to the net present value metric that may be more intuitive for some users. It simply converts the lump sum net present values to an annual equivalent. The value is only roughly similar to dividing the treatment gain (or loss) in a given year by the number of years to that point in the simulation; the approach here properly incorporates discounting considerations. For example, if a treatment loss of $\$ 200$ were estimated at year 20, a simple approach would suggest an annual cost of approximately $\$ 10$ per year for that 20-year period to maintain the tree-but this would not account for the time value of money. Using Formula 2 and a $4 \%$ discount rate, the $\$ 200$ value is equivalent to an annual expenditure of $\$ 14.71$. This value provides model users with a more accurate alternative metric to help assess their willingness to pay for treatments over a given period of time. Thus, based on the above example, a homeowner could consider whether his/ her tree is worth spending $\sim \$ 200$ over 20 years, or alternatively and equivalently, whether he or she is willing to pay about $\$ 14.71$ per year over that time period to conserve/protect the tree.

It is worth noting that this model does not incorporate all the benefits that have been attributed to urban trees (see MacPherson et al. 2007 for a detailed discussion). Some of these benefitssuch as aesthetic, psychological, and sentimental values-are highly subjective, vary significantly among individuals, and are difficult to quantify in money terms. Nonetheless, many of these contribute to the overall existence (or intrinsic) value (Krutilla 1967) that a homeowner may place on a tree; in some cases, this existence value may indeed be large enough to justify substantial expenditures toward conserving a tree. A negative treatment gain value (and/or its annual equivalent) can be interpreted as the minimum value a homeowner would have to be willing to pay to justify treating a tree over that period of time. This has been coined here as a "break-even existence value," revealing the dollar amount required to maintain the "existence" of the tree. The term "existence value" is well known in economics-here it simply reflects the annual cost of maintaining the existence of the ash or, stated alternatively, the additional annual financial burden of maintaining the tree should the various benefits not cover the costs. 
As with any model, the one presented here includes various sources of uncertainty that may affect the accuracy of, and confidence in, the outputs. For certain inputs, such as removal, replacement, and treatment costs, uncertainty can be minimized by obtaining quoted estimates from reputable arborists. However, other sources of uncertainty previously mentioned, such as the extended benefit and cost values of MacPherson et al. (2007) and the tree growth equations based on plantation data, are more challenging to reduce. Formal estimates of the uncertainty are not provided (e.g., confidence intervals), but users are reminded that uncertainty is inherent in model outputs. Sensitivity analyses, such as those presented here, can help understand the implications of these uncertainties.

\section{RESULTS AND DISCUSSION}

The model produces an output table that shows all costs and benefits through time as well as the net treatment gains/losses and equivalent annual values. Table 2 presents these outputs from a model run that was parameterized using the values provided in Table 1; a review of the derivation and interpretation of these values is as follows. The present value of treatment costs was accumulated through time (reaching $\$ 2204$ by year 30) as treatments were applied once every two years (i.e., biennially). These costs were tied to tree $\mathrm{DBH}$ and thus increase as the tree grows during the simulation; however, these increases are offset by economic discounting which causes the magnitude of the biennial increments to decline over time. Multiplying the home's potential sale price $(\$ 340,000)$ by the estimated contribution of a mature tree $(0.5 \%)$ gives the home value benefit in the first year of the simulation (\$1700); in Table 1, this value declines over time due to discounting. Under the removal/replacement scenario, there is an immediate loss in home value when the tree is cut at year two, but this value is gained back over time in proportion to the DBH of the replacement tree-so that, for example, a replacement tree with a DBH of $10 \mathrm{~cm}$ would contribute half of the home value benefit generated by a mature tree $(20 \mathrm{~cm})$. Note that, once mature, the tree's contribution to home value was capped at $0.5 \%$; no evidence was found in the literature to support a continued increase in home value in proportion to $\mathrm{DBH}$. In fact, one study reported reduced home values in relation to large trees (Orland et al. 1992). It should be stressed that home value benefits are only realized in a financial sense if a house is sold and thus may only be relevant if a homeowner is selling, or wants to consider the option of selling his/her house. The remaining benefits and costs (i.e., energy, runoff and pollution, and maintenance) in any given year of the simulation are driven by tree age (as illustrated in Figure 1) and economic discounting; note that the age of the existing ash tree is estimated from the input $\mathrm{DBH}(30 \mathrm{~cm})$ by rearranging Formula 1. Treatment gain (or loss) is calculated by subtracting the summed removal-and-replacement costs and benefits from the summed treatment costs and benefits; this is then converted to the equivalent annual value using Formula 2.

To assist in interpreting these results, note again that the net treatment gain/loss is the dollar amount that a homeowner would be ahead/behind by treating a tree for a given number of years. For example, to conserve the tree presented in Table 2 for 25 years, it would cost an estimated $\$ 648$ more than the removal and replacement approach; alternatively, this amount could be expressed as an annual equivalent (or annuity) of $\sim \$ 39 /$ year.
This is the additional amount that a model user would have to be willing to pay to conserve the existing ash tree over that period of time-what has been termed the break-even existence value. The net treatment gain/loss metric and its annual equivalent are particularly useful when applied to a specific time horizon. For instance, if a homeowner is considering selling his/her home at some point in the future, these measures can provide insights on the economic attractiveness of treating a tree up to that point in time. Similarly, recent studies suggest that EAB populations may crash after available ash resources have been depleted-approximately 10 years after initial infestation (Knight et al. 2008) - at which point homeowners may be able to reduce the frequency of treatments; clearly this possibility will need to be revisited in the future as research into $\mathrm{EAB}$ population dynamics progresses.

To further illustrate the model, graphical model outputs for small $(15 \mathrm{~cm} \mathrm{DBH})$, medium $(30 \mathrm{~cm})$ and large $(45 \mathrm{~cm})$ ash trees are presented (Figure 2). Using default model values (Table 1) and only the basic cost considerations (i.e., none of the extended costs and benefits), treatment gains remained positive until year 11, 7 , and 7, for small, medium, and large trees, respectively (Figure 2a). Inclusion of the extended benefits and costs greatly changed these outcomes, with positive treatment gains for small, medium, and large trees persisting until years 19,17 , and 15 respectively (Figure 2b). Due to space considerations, the results published here are only for the basic cost considerations and the combined suite of extended benefits and costs; however, the online version of the model allows users to select specific extended benefits and costs and provides a separate graphical output for each.

These results lead to the perhaps counterintuitive finding that treating a small tree can, in some circumstances, be more attractive than treating a large tree (Figure 2). Relevant default parameter values for a small tree include a removal cost of $\$ 240$ and an initial treatment cost of $\$ 97.50$; for a large tree, these values increase to $\$ 900$ for removal and $\$ 292.50$ for initial treatment. One might expect that the lower removal cost would make removal more appealing for smaller trees; the analysis suggests that the lower treatment cost can override this effect. This finding is, of course, entirely dependent on the default values outlined above. Kovacs et al. (2010), using a dynamic-programming approach, determined that the optimal course of action was to remove trees less than $30 \mathrm{~cm} \mathrm{DBH}$ and treat otherwise. These divergent conclusions result primarily from the much lower treatment costs employed in the Kovacs et al. (2010) study.

A simple sensitivity analysis was employed to investigate the influence of each input variable on the duration of treatment gains [i.e., the number of years that the treatment approach is financially ahead of removal and replacement (Table 3)]. Since both benefits and costs are discounted, varying the discount rate between $2 \%$ (considered relatively low) and $10 \%$ (considered relatively high) had very little effect on the duration for which treatment gains were projected. However, at even higher discount rates (e.g., $15 \%$; not shown), positive treatment gains extend beyond the 30 -year time horizon used in this analysis. This result underlines the fact that high discount rates significantly lower the present value of future costs relative to current benefits; thus, homeowners with very high time preference rates on expenditures should carefully consider the merits of treating their ash.

Treatment costs had the largest impact on the duration of positive treatment gains (Table 3 ). Values of $\$ 5.00$, $\$ 6.50$, and $\$ 8.00$ per $\mathrm{cm} \mathrm{DBH}$ resulted in positive treat- 
ment gains until years 21,17 , and 13 , respectively. Treatment frequencies (which are closely linked to treatment costs) of one, two, and three years resulted in positive treatment gains that persisted until years 9,17 , and 23 , respectively (Table 3 ). These findings, along with those discussed for Figure 2, emphasize the importance of treatment cost to the economic attractiveness of the treatment approach.

Removal costs of $\$ 340, \$ 540$, and $\$ 740$ for a medium-sized ash resulted in positive treatment gains persisting through years 15,17 , and 19 , respectively (Table 3 ). Since removal is a one-time initial cost, there was a consistent improvement in the duration of positive treatment gains of about one year for every $\$ 100$ increase in removal costs. Increasing removal lag times (i.e., the number of years that removal costs can be delayed relative to treatment costs) from zero to four years only slightly reduced the duration of treatment gains (Table 3). This result was related to savings that resulted from discounting the lagged removal and replacement costs. For example, with a lag of zero years, the default removal and replacement cost for a medium ash is $\$ 940$; with a lag of four years, the present value of that cost drops to about $\$ 800$ based on a $4 \%$ discount rate, which translates into about two fewer years of treatment gains for the lagged scenario.

Varying the percentage of value added to a home due to the presence of a mature tree had a modest impact on the duration of treatment gains (Table 3). This result is influenced by both the discount rate, which reduces the magnitude of future home value benefits, and the growth of the replacement tree, which is anticipated to return full home value by the time it has a DBH of $20 \mathrm{~cm}$ - at about 30 years

Table 2. Example output values from a model run that estimates the costs and benefits of treating an existing ash tree versus the costs and benefits of removing the ash and replanting a deciduous tree in the same location. The model input values used to produce these results are provided in Table 1. See text for details on the derivation and interpretation of table values. Currency is expressed in 2010 Canadian dollars.

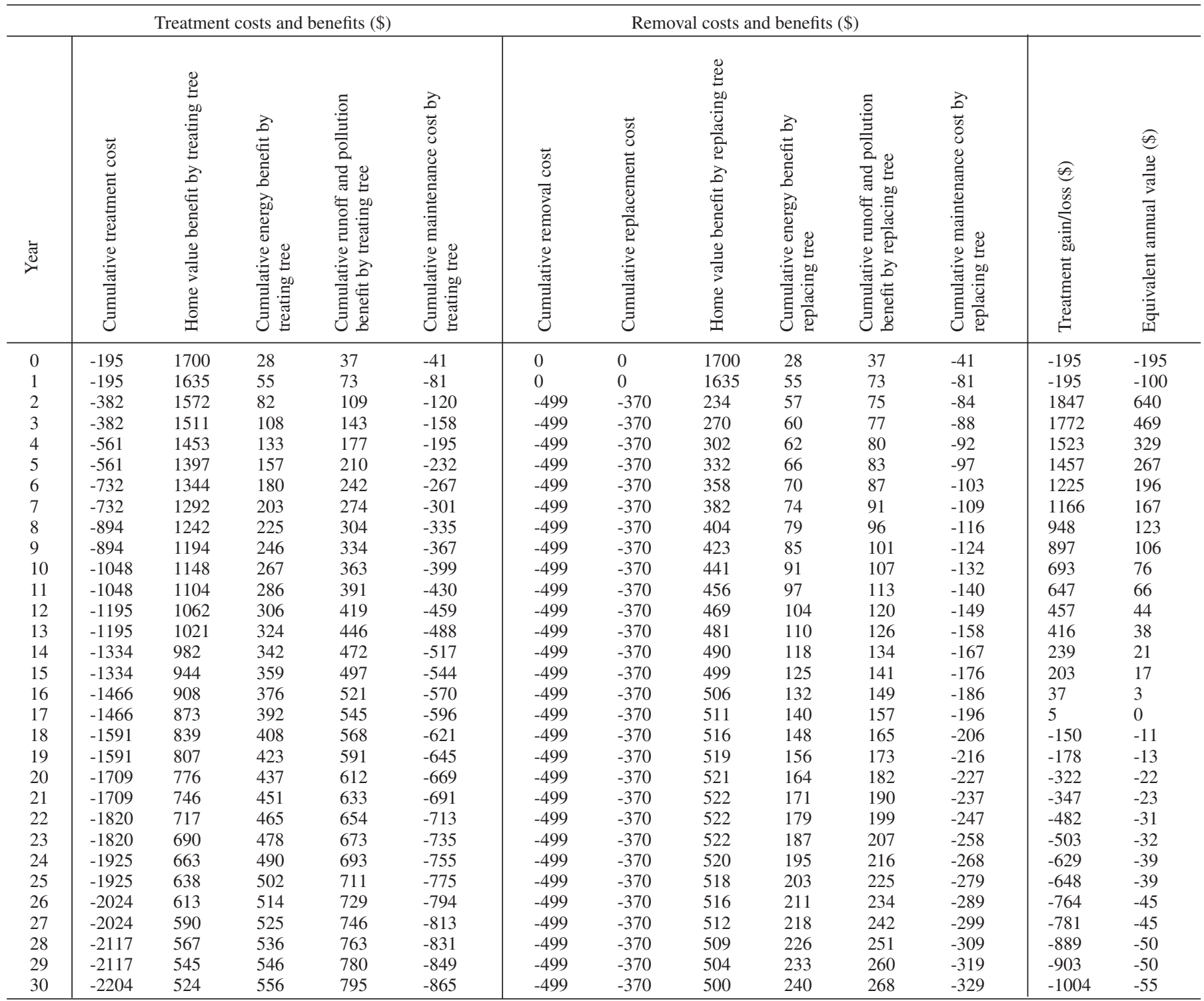


of age based on the growth curve employed in the model. Again these home value benefits are only realized in a financial sense if the house is sold. Note however, the presence of an ash tree may act as a disincentive to some buyers.

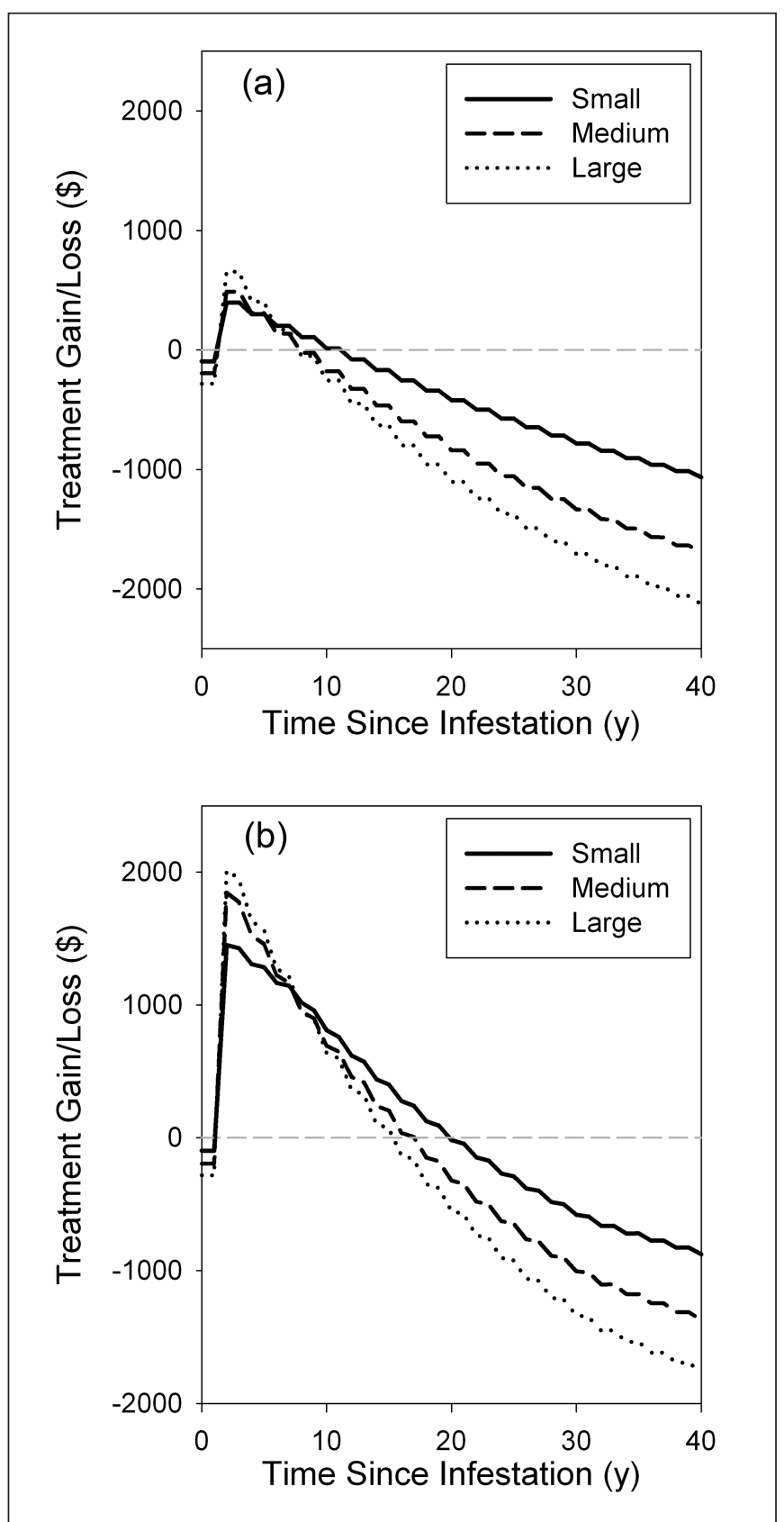

Figure 2. The duration of treatment gains associated with treating a small (20-years-old; $15 \mathrm{~cm} \mathrm{DBH),} \mathrm{medium} \mathrm{(45-years-old;} 30 \mathrm{~cm}$ DBH), and large (75-years-old; $45 \mathrm{~cm} \mathrm{DBH}$ ) ash tree. Results are shown for a) basic costs and b) extended costs and benefits (see text for details). The point where the line crosses the $x$-axis is the time at which accumulated treatment costs equal the estimated cost of removal-and-replacement.
Table 3. Variation in the duration of treatment gains induced by using three plausible values for each of six model parameters (while holding all other parameters at the example values provided in Table 1). Currency is expressed in 2010 Canadian dollars.

\begin{tabular}{llc}
\hline Model parameter & Value & $\begin{array}{c}\text { Duration of } \\
\text { treatment gains (y) }\end{array}$ \\
\hline Discount rate (\%) & 2 & 16 \\
& 4 & 17 \\
Treatment cost & 10 & 17 \\
(\$/cm DBH) & 5 & 21 \\
& 6.50 & 17 \\
Treatment & 8 & 13 \\
frequency (y) & 1 & 9 \\
& 2 & 17 \\
Removal cost (\$) & 3 & 23 \\
& 340 & 15 \\
Removal lag (y) & 540 & 17 \\
& 740 & 19 \\
Home value & 0 & 17 \\
contribution $(\%)$ & 2 & 17 \\
& 4 & 15 \\
& 0.25 & 13 \\
\end{tabular}

\section{CONCLUDING COMMENTS}

The model presented here is intended to assist users with decisions about protecting their ash trees. Although such decisions can be highly subjective and involve considerable uncertainty, the model helps to frame and quantify important costs and benefits. Several general guidelines emerge from these particular analyses. First, the inclusion of extended costs and benefits associated with urban trees greatly changes the attractiveness of the treatment approach; homeowners concerned about these factors may wish to seriously consider quantifying such values to support their decisions around ash protection. Second, small ash trees (around $10-20 \mathrm{~cm} \mathrm{DBH}$ ) appear to be surprisingly good candidates for protection because they may incur lower treatment costs than larger trees. Clearly this conclusion will vary with the actual treatment, removal, and replacement costs for a given tree, but ash owners should consider treatment for all tree sizes. Third, ash owners who have very strong preferences for minimizing current expenditures, and thus implicitly have a high discount rate, may wish to consider protecting their ash simply because it could result in a series of smaller, delayed payments compared to removal and replacement. Finally, the decision to treat or remove a tree is highly sensitive to the treatment cost; thus, all else being equal, ash owners considering treatment should always try to secure the best possible rate from available applicators.

There are a number of avenues for further model development. As noted, the tree growth equations employed in the model are based on data from plantations, not urban settings; efforts are underway to incorporate urban growth data into the model. Also, the current model has been developed for decisions pertaining to a single tree. While, in principle, an owner with multiple ash trees could explore basic cost considerations by entering total removal, replacement, and treatment costs into the model, a significant upgrade would allow a more nuanced approach to this situation, such as a routine to optimize the number of trees treated/removed (see Sadof et al. 2011). Another potential enhancement would allow homeowners to explore the financial implications of treating their 
existing ash for a specified period of time before removing it, perhaps to delay removal costs until funds are available, to see how the local infestation progresses, or in anticipation of improved (or less costly) treatment options. Given that EAB control is a topic of ongoing intensive study, the concept of buying time is important.

The model is available as an internet application (CFS-APM: Canadian Forest Service - Ash Protection Model, see: http:// gmaps.nrcan.gc.ca/apm/index.php). The tool has generated considerable interest and feedback from municipal representatives and homeowners providing motivation to continue upgrading the application over time. Although targeted at homeowners, it may be of interest to a range of other tree care professionals. For instance, arborists and consulting foresters could use the model to assist homeowners in making more informed decisions about the fate of infested ash trees. Municipal foresters could also use the model for decisions concerning specific trees; however, the EAB cost calculator developed by Sadof et al. (2011) is currently better suited for multi-tree decisions. Finally, the model may be of use in forestry extension efforts that aim to educate the public on the various benefits associated with urban trees.

Acknowledgments. We thank: Joe Meating for providing information on TreeAzin costs, application rates, and efficacy; Ken Farr, Jacques Gagnon and two anonymous reviewers for editorial feedback; Barry Lyons for advice on matters of EAB biology; Geoff McLeod, Bill Roesel, Jason Pollard, John McNeil, and Richard Ubbens for feedback on tree removal and replacement costs; Kevin Lawrence and Kathy Campbell for technical support; and Saul Fraleigh and Darren Allen for assistance with the plantation growth equations used in the model. Any errors remain the responsibility of the authors.

\section{LITERATURE CITED}

Anderson, L.M., and H.K. Cordell. 1985. Residential property values improved by landscaping with trees. Southern Journal of Applied Forestry 9:162-166.

Anderson L.M., and H.K. Cordell. 1988. Influence of trees on residential properties in Athens, Georgia (U.S.A.): A survey based on actual sales prices. Landscape and Urban Planning 15(1):153-164.

Anulewicz, A.C., D.G. McCullough, and D.L. Cappaert. 2007, Emerald ash borer (Agrilus planipennis) density and canopy dieback in three North American ash species. Arboriculture \& Urban Forestry 33:338-349.

Bioforest. 2011. TreeAzin systemic insecticide. Accessed 08/18/2011. $<$ www.bioforest.ca>

Boardman A.E., D.H. Greenberg, A.R. Vining, and D.L. Weimer. 2001. Cost-benefit analysis: Concepts and practice. Prentice Hall: Upper Saddle River, New Jersey. 526 pp.

Canadian Food Inspection Agency. 2010. Emerald Ash Borer-Agrilus planipennis. Accessed 02/09/10. <www.inspection.gc.ca/english/ plaveg/pestrava/agrpla/agrplae.shtml>

Canadian Real Estate Association. 2010. MLS Statistics. Accessed 05/27/2011. <www.crea.ca/public/news_stats/statistics.htm>

Cappaert, D., D.G. McCullough, T.M. Poland, and N.W. Siegert. 2005. Emerald ash borer in North America: A research and regulatory challenge. American Entomologist 51:152-165.

Dwyer, J.F., E.G. McPherson, H.W. Schroeder, and R.A. Rowntree. 1992. Assessing the benefits and costs of the urban forest. Journal of Arboriculture 18(5):227-234.
Herms, D.A., D.G. McCullough, D.R. Smitley, C. Sadof, R.C. Williamson, and P.L. Nixon. 2009. Insecticide Options for Protecting Trees From Emerald Ash Borer. North Central IPM Centre Extension Bulletin. Accessed 05/16/2011. <www.emeraldashborer.info>

Knight, K.S., R.P. Long, A. Smith, K. Gandhi, J. Rebbeck, and D.A. Herms. 2008. How fast will the trees die? A transition matrix model of ash (Fraxinus spp.) decline in forest stands infested by emerald ash borer (Agrilus planipennis). In: Proceedings, Emerald ash borer research and technology development meeting. pp. 28-29. Pittsburgh, PA. 23-24 Oct. 2007. Abstract.

Kovacs, K.F., R.G. Haight, D.G. McCullough, R.J. Mercader, N.W. Siegert, and A.M. Liebhold. 2010. Cost of potential emerald ash borer damage in U.S. communities, 2009-2019. Ecological Economics 69:569-578.

Krutilla, J. 1967. Conservation Reconsidered. The American Economic Review 57:777-786.

McKenney, D.W., J.H. Pedlar, D. Yemshanov, D.B. Lyons, K. Campbell, and K. Lawrence. 2012. Estimates of the potential cost of emerald ash borer (Agrilus planipennis Fairmaire) in Canadian municipalities. Arboriculture \& Urban Forestry 38(3):81-91.

McKenney, D.W., D. Allen, S. Fraleigh, J.H. Pedlar, and K. Campbell. 2008. Growth of souththern Ontario hardwood research plantations. Great Lakes Forestry Centre, Information Report GLC-X-9E. 53 pp.

McKenzie, N., B. Helson, D. Thompson, G. Otis, J. McFarlane, T. Buscarini, and J. Meating. 2010. Azadirachtin: An effective systemic insecticide for control of Agrilus planipennis (Coleoptera: Buprestidae). Journal of Economic Entomology 103:708-717.

McPherson, G.E., J.R. Simpson, J.J. Peper, S.L. Gardner, K.E. Vargas, and Q. Xiao. 2007. Northeast community tree guide: benefits, costs, and strategic planting. Gen. Tech. Rep. PSW-GTR-202. Albany, CA: U.S. Department of Agriculture, Forest Service, Pacific Southwest Research Station. $106 \mathrm{pp}$

Orland, B., J. Vining, and A. Ebreo. 1992. The effect of street trees on perceived values of residential property. Environment and Behavior 24:298-325.

Portney, P.R., and J.P. Weyant. 1999. Discounting and intergenerational equity. Resources for the Future 186 pp.

Prasad, A.M., L.R. Iverson, M.P. Peters, J.M. Bossenbroek, S.N. Matthews, T. Sydnor, and M.W. Schwartz. 2010. Modeling the invasive emerald ash borer risk of spread using a spatially explicit cellular model. Landscape Ecology 25:353-369.

Sadof, C.S., L. Purcell, F.J. Bishop, C. Quesada, and Z. Zhang. 2011. Evaluating restoration capacity and costs of managing the emerald ash borer with a web-based cost calculator in urban forests. Arboriculture \& Urban Forestry 37:74-83.

Scott, J.L., and D.R. Betters. 2000. Economic analysis of urban tree replacement decisions. Journal of Arboriculture 26(2):69-76.

Siegert, N.W., D.G. McCullough, A.M. Liebhold, and F.W. Telewski. 2007. Resurrected from the ashes: an historical reconstruction of emerald ash borer dynamics through dendrochronological analysis. In: V. Mastro, R. Reardon, and G. Para (Eds.). Proceedings of the emerald ash borer/Asian longhorned beetle research and technology development meeting. FHTET-2007-04. USDA Forest Service, Morgantown,WV. pp. 18-19.

Sydnor, T.D., M. Bumgardner, and S. Subburayalu. 2011. Community ash densities and economic impact potential of emerald ash borer (Agrilus planipennis) in four midwestern states. Arboriculture \& Urban Forestry 37(2):84-89. 
Thériault, M., Y. Kestens, and F. Des Rosiers. 2002. The impact of mature trees on house values and on residential location choices in Quebec city. In: A.E. Rizzoli and A.J. Jakeman (Eds.). Integrated Assessment and Decision Support: Proceedings of the First Biennial Meeting of the International Environmental Modelling and Software Society 2:478-483. Accessed 05/16/2011. <www.iemss.org/iemss2002/proceedings/pdf/volume\%20due/191.pdf $>$

Yang, Z., X. Wang, J.R. Gould, R.C. Reardon, Y. Zhang, G. Liu, and E. Liu. 2010. Biology and behavior of Spathius agrili, a parasitoid of the emerald ash borer, Agrilus planipennis, in China. Journal of Insect Science 10:30.

Daniel W. McKenney (corresponding author)

Natural Resources Canada, Canadian Forest Service

Great Lakes Forestry Centre

1219 Queen Street East

Sault Ste. Marie, ON, P6A 2E5, Canada

Dan.McKenney@NRCan.gc.ca

\section{John H. Pedlar}

Natural Resources Canada, Canadian Forest Service

Great Lakes Forestry Centre

1219 Queen Street East

Sault Ste. Marie, ON, P6A 2E5, Canada

Zusammenfassung. Hier wird ein Model präsentiert, welches helfen soll, über das Schicksal von Eschen zu entscheiden, welche durch die Invasion des Eschenbohrers (Agrilus planipennis) in Nordamerika betroffen sind. Das Modell analysiert laufende Behandlungskosten versus einmaliger Kosten, die mit der Fällung und der Ersatzpflanzung auftreten. Alle zukünftigen Werte werden entsprechend der allgemeinen ökonomischen Praxis diskontiert. Für jedes Jahr innerhalb einer Zinsperiode wird der Netto-Behandlungsgewinn bzw.- verlust kalkuliert mit Hinweis auf die Zeitspanne, die ein Eigentümer entweder finanziell im Plus oder Minus liegt, wenn er seine Esche behandeln lässt. Das Modell wurde veröffentlicht und zeigte Ergebnisse auf für Werte, die unter kanadischen Bedingungen zu erwarten wären, wo die Behandlungsoptionen etwas mehr eingeschränkt sind als in den Vereinigten Staaten. Optionale Modelleigenschaften beinhalten Grundstückswerte, Energieeinsparungen, Vorteile bei Bodenabtrag durch Regen und Schadstoffeintrag, sowie die laufenden Unterhaltungskosten. Wenn diese ausgedehnten Vorteile und Kosten in das Modell einbezogen werden, gibt es für eine Esche mittlerer Größe für die folgenden 17 Jahre eine positive Bilanz durch die Behandlung. Negative Werte können interpretiert werden als „break-even existence value“, eine Summe, die ein Hauseigentümer zur Verfügung stellen müsste, um seine Esche zu retten, wenn andere Vorteile bei der Kompensation der auftretenden Kosten versagen würden. Eine interaktive Version des Modells kann online abgerufen werden: (http://gmaps. nrcan.gc.ca/apm/index.php).

Resumen. Se presenta un modelo que fue desarrollado para ayudar a los usuarios a decidir la suerte de fresnos (Fraxinus spp.) amenazada por la llegada del barrenador Esmeralda del Fresno (Agrilus planipennis Fairmaire) en América del Norte. Básicamente, el modelo realiza un seguimiento de los gastos del tratamiento de un árbol con un insecticida frente a los costos de una sola vez asociados con la eliminación y sustitución. Opcionalmente, los usuarios pueden incluir los costos y beneficios de otros, extendidas en el modelo que se han atribuido a árboles urbanos, incluyendo: primas de valor de propiedad, ahorro de energía, beneficios de escorrentía y contaminación y los costos de mantenimiento. Para cada año, en un horizonte de tiempo de 30 años, se calcula el tratamiento neto pérdidas/ganancias y se trazan indicando el período de tiempo que el dueño de casa podría estar financieramente delante/detrás por el tratamiento de un árbol con un insecticida. Se proporcionan los valores por defecto que describen los costos promedio que podrían esperarse en Canadá, pero éstos pueden reemplazarse por los usuarios si hay disponible mejor información para su propia situación y ubicación. Una versión interactiva del modelo está disponible en línea (http://gmaps. nrcan.gc.ca/apm/index.php). 